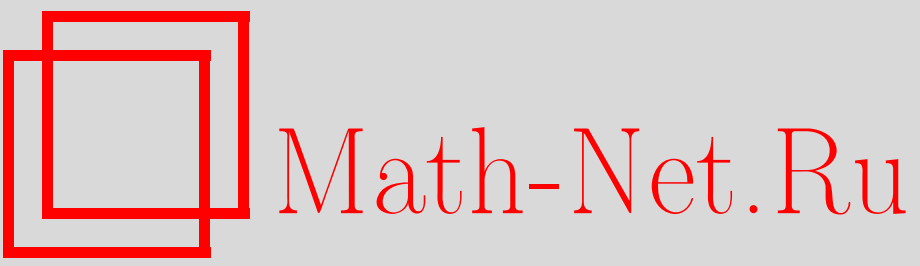

Д. В. Аносов, В. Л. Гинзбург, А. Б. Жижченко, М. И. Монастырский, С. П. Новиков, Я. Г. Синай, М. А. Соловьев, Наум Натанович Мейман (некролог), УМH, 2002, том 57, выпуск 2, 179-184

DOI: https://doi.org/10.4213/rm499

Использование Общероссийского математического портала Math-Net.Ru подразумевает, что вы прочитали и согласны с пользовательским соглашением

http: //www. mathnet.ru/rus/agreement

Параметры загрузки:

IP : 3.80 .181 .102

26 апреля 2023 г., 16:45:40 


\section{НАУМ НАТАНОВИЧ МЕЙМАН}

31 марта 2001 г. на 89 году жизни скончался профессор Н.Н. Мейман, крупньй математик, автор фундаментальных результатов в теории функций комплексного переменного, уравнений в частных производных и математической физике. Наум Натанович принадлежит к первому поколению математиков, сформировавшемуся при Советской власти. Это обстоятельство наложило отпечаток на его весьма драматическую научную судьбу со всеми ее взлетами и падениями. Наум Натанович родился 12 мая 1912 г. в местечке Базар Киевской губернии в семье лесоторговца. Один из двух его братьев был связан с социал-демократическими революционными кругами и в дальнейшем работал экономистом. В 1928 г., приписав себе лишний год, Наум Натанович отправился поступать в Московский университет на физико-математический факултет. В это время уже действовали правила, затруднявшие поступление в вузы детей из "буржуазных" семей, и для того, чтобы обойти это препятствие, Наум Натанович запасся, с помощью брата, письмом к председателю экзаменационной комиссии от какого-то видного украинского большевика. Как он впоследствии рассказьвал, благодаря его наивности и неопытности, это письмо сыграло с ним злую шутку. Вместо того, чтобы отдать письмо прямо в руки председателю, он передал его секретарю. Придя на экзамен, он увидел стенгазету, где под заголовком "Блату бой" было помещено его рекомендательное письмо. В итоге к экзаменам Наум Натанович допущен не был, но ему удалось поступить в Плехановский институт. Спустя год он все же перевелся на физмат МГУ, но вскоре был исключен из него по доносу. Процесс исключения был весьма специфичен. Летом на военные сборы, где находились студенты, прибыла комиссия, одной из задач которой было разобраться с “делом Меймана”. В спецотделе части ему среди прочего был задан вопрос: как он относится к Советской власти? С непосредственностью молодого человека, во многом сохранившейся у него до конца жизни, он ответил, что относится к Советской власти лояльно, после чего и был с позором изгнан из университета. Как ни наивно звучит этот ответ, он верно отражает отношение к власти Наума Натановича и многих других представителей научной интеллигенции его поколения.

Дальнейшие события показали, что этот огорчительный эпизод, кардинально изменивший жизнь Наума Натановича, в целом имел положительное значение. По рекомендации Н. И. Ахиезера, которого он знал с детства, Наум Натанович отправляется "подальше от греха" в Казань к Н.Г. Чеботареву, крупному математику и прекрасному человеку. Сдав экстерном за год весь университетский курс, он становится аспирантом Н. Г. Чеботарева и параллельно начинает преподавать в Казанском авиационном институте. Годы аспирантуры во многом определили дальнейшую научную карьеру Наума Натановича. Н.Г. Чеботарев предложил ему интересную и перспективную тему, связанную с проблемой Раусса-Гурвица. Науму Натановичу удалось по- 
лучить важные результаты, которые он оформил в 1937 г. в качестве кандидатской диссертации. Работа была признана столь значительной, что ему сразу была присвоена степень доктора физико-математических наук. Через два года, в возрасте 27 лет, он становится профессором. В 1938 г. за этот цикл работ Науму Натановичу присуждается первая премия на Всесоюзном конкурсе, организованном ЦК ВЛКСМ. За год до защиты диссертации он переехал в Харьков, где 2 года проработал в институте математики при Харьковском университете. Этот период жизни Наум Натанович всегда вспоминал с удовольствием. Здесь он познакомился с Л. Д. Ландау, дружба с которым продолжалась вплоть до преждевременной кончины великого физика ${ }^{1}$. В 1938 г. Наум Натанович переезжает в Москву, где в течение ряда лет заведует кафедрой математики в ряде вузов, а с 1939 по 1941 г. работает по совместительству в Математическом институте им. В. А. Стеклова. В годы войны он находился в эвакуации, заведуя кафедрой математики военного училища. Вернувшись в Москву в конце войны, он сначала работает в Институте физической химии АН CCCP, а с 1947 г. в Институте физических проблем, в должности начальника математической лаборатории, входившей в теоретический отдел, возглавляемый Ландау. Лаборатория занималась расчетами, связанными с созданием атомной бомбы. Математические работы этого периода нашли отражение в совместном докладе Л. Д. Ландау, Н. Н. Меймана и И. М. Халатникова, прочитанном Наумом Натановичем на 3-м Всесоюзном математическом съезде в 1956 году. За эти работы авторы получили в 1952 г. Сталинскую премию 2-й степени. В 1955 г., после возвращения П. Л. Капицы в ИФП, математическая лаборатория была расформирована, а Наум Натанович был переведен в Теплотехническую лабораторию АН СССР, возглавляемую А. И. Алихановым, позднее преобразованную в Институт теоретической и экспериментальной физики. В этом институте он проработал вплоть до 1975 г., когда решил эмигрировать в Израиль. Ему было отказано в выезде по формальной причине, связанной со старыми работами над бомбой. В попытках выехать Наум Натанович постепенно перешел из положения "отказника" в активного деятеля правозащитного движения. Он стал членом Сахаровского комитета по защите прав человека и в период ссылки А. Д. Сахарова в Горький возглавлял его. В этой работе он проявил себя как смелый и принципиальный человек. При этом Наум Натанович продолжал активную научную работу. Он опубликовал в этот период несколько научных работ (см. [59], [60]) и был одним из организаторов научного семинара “отказников", труды которого были изданы за границей. Длительная борьба за выезд, которую поддерживали многие крупные западные ученые (Л. Шварц, А. Мартен и др.) закончилась лишь в 1988 г., когда демократическая перестройка и распад СССР решили проблему автоматически. К сожалению, годы изнурительной борьбы и возраст сделали свое дело. В Израиле Наум Натанович чувствовал себя довольно одиноко, несмотря на оказанный ему теплй прием ${ }^{2}$ и должность почетного профессора. До последних дней он живо интересовался наукой и происходящими в России событиями, которые воспринимал исключительно эмоционально. Его последняя научная работа [62] посвящена математическим основам функционального интегрирования и была представлена на мемориальную Сахаровскую конференцию в 1996 году.

Научные достижения Наума Натановича относятся в основном к трем областям: теории функций комплексного переменного, теории уравнений в частных производных и математической физике. Особенностью его исследований является получение весьма общих результатов, стартуя с конкретной трудной и актуальной задачи. Первый цикл принадлежащих ему работ связан с проблемой Раусса-Гурвица, которая в ее классической постановке, восходящей к Максвеллу (1868 г.) состоит в нахождении условий на коэффициенты полинома, при которых его корни имеют отрицательные вещественные части. Решению этой задачи были посвящены работы крупнейших математиков XIX и XX столетий, включая Раусса, Гурвица, Шура и др. Позднее в связи с нуждами автоматического регулирования (а затем и радиотехники) стал актуальным аналогичньй вопрос, относящийся к квазиполиномам, который заинтересовал Н. Г. Чеботарева. В 1942 г. он вел посвя-

\footnotetext{
${ }^{1}$ Весьма компетентным свидетельством их дружбы является письмо начальника управления КГБ СССР заведующему отделом ЦК, содержащее записи результатов прослушивания разговоров Ландау с близкими друзьями. Значительная часть этого уникального документа, датированного 1956 г., отведена разговорам с Наумом Натановичем.

${ }^{2}$ В 1992 г. в связи с его восьмидесятилетием в Тель-Авивском университете была организована конференция в его честь.
} 
щенньй этой задаче семинар, в котором помимо казанских ученых участвовали эвакуированные в Казань иногородние математики, включая Л. С. Понтрягина. Последний провел исследование проблемы Раусса-Гурвица для частного, но важного случая, когда показатели квазиполинома соизмеримы. В общем случае, изученном Н.Г. Чеботаревым и Наумом Натановичем, пришлось привлекать иные методы, связанные с анализом данной проблемы для более широкого класса целых функций. Заслуга Наума Натановича как раз и состоит в выделении наиболее общего класса целых функций, на который эта проблема допускает естественное распространение - так называемого класса $B$-функций, - и в ее эффективном решении в такой постановке. Использование $B$-функций позволило ему получить фундаментальные результаты для еще одного круга классических задач, состоящих в построении целых функций, наименее уклоняющихся от нуля. Результаты этих двух циклов исследований суммированы в работах [15], [35]. Книга [15], написанная Наумом Натановичем в соавторстве со своим учителем Н. Г. Чеботаревым (причем Науму Натановичу принадлежат теоретико-функциональные главы), представляет собой образцовое изложение решения труднейшей математической проблемы и является первым систематическим изложением теории целых функций, демонстрирующим на конкретном примере эффективность общих теорем комплексного и функционального анализа. Найденньй Наумом Натановичем класс $B$-функций оказался весьма полезным и при анализе спектра уравнения Шредингера с комплексным периодическим потенциалом, выполненном им в работе [59], где получены также формулы разложения по собственным функциям соответствующего оператора.

Еще один цикл работ, где Наум Натанович существенно опередил свое время, состоит в изучении устойчивости и сходимости метода сеток при решении задачи Коши для линейных и квазилинейных уравнений в частных производных [22]-[24]. Эти работы возникли из сугубо прикладных проблем, связанных с расчетом мощности взрьва атомных и водородных бомб и по условиям секретности были опубликованы, и то далеко не полностью, лишь спустя несколько лет после написания.

Из результатов Наума Натановича в области математической физики следует выделить работу [40], где установлены наиболее общие предположения, при которых справедлива известная теорема Померанчука об асимптотическом равенстве полных сечений взаимодействия частицы и античастицы с одной и той же мишенью при возрастании энергии частиц. Предложенное им доказательство, в отличие от прежних, не опиралось на дисперсионные соотношения и использовало лишь общие свойства аналитических функций, а в статье [45] он распространил результат на дифференциальные сечения. В ходе этого исследования Наум Натанович установил [48], [49] высокоэнергетические ограничения на амплитуды рассеяния, вытекающие из локальности взаимодействия и принципа причинности. Выделяемый найденными им ограничениями класс квантовых полей оказался значительно шире операторнозначных распределений Шварца, обычно используемых в квантовой теории поля, и соответствовал гиперфункциям Сато-Мартино. Существенно, что как раз на этот класс обобщенных функций естественньм образом распространяется известная теорема Боголюбова "об острие клина" [52]. Эти результаты явились предвестником развитой значительно позже формулировки локальной теории поля в терминах гиперфункций Фурье. Кроме того, они положили начало принципиально новому направлению в нелокальной квантовой теории, в котором нелокальность связывалась с высокой сингулярностью взаимодействия на малых расстояниях, соответствующей экспоненциальному росту матричных элементов полей в импульсном пространстве. Именно такой рост, с показателем экспоненты, пропорциональным планковской длине, был впоследствии обнаружен у пропагаторов в теории суперструн, которая в настоящее время считается наиболее фундаментальной теорией взаимодействия. Научные достижения Наума Натановича далеко не исчерпьваются перечисленными результатами. Активно взаимодействуя с физиками в ИТЭФе, он выполнил целый ряд работ, имеющих важное прикладное значение. Это и созданный вместе с его сотрудниками уникальный атлас вычисления фазовых объемов в процессах столкновения частиц [52] и работа [57] по применению метода перевала для табулирования специальных функций (в частности, функций Бесселя с произвольным значением индекса) и др. Его дружеская помощь физикам нашла отражение и в знаменитом курсе теоретической физики Л. Д. Ландау и Е.М. Лифшица, где в томе "Статистическая физика" им написан раздел о дисперсионных соотношениях. Нельзя не упомянуть и его замечательньй, первый и до сего времени единственньй перевод трудов Э. Галуа на русский язьк. 
Так получилось, что Наум Натанович, будучи по образованию чистым математиком, почти всю жизнь работал в физических институтах. Сейчас, когда контакты математиков и физиковтеоретиков стали столь тесными, что в некоторых областях трудно провести грань между работой тех и других, нельзя не вспомнить, что еще 30 лет назад ситуация была совсем иной. Наума Натановича можно смело отнести к пионерам этого прогрессивного и полезного для обеих наук взаимодействия. $\mathrm{K}$ сожалению, положение математика среди физиков несколько мешало более широкому признанию в математическом мире его работ, многие из которых не устарели и заслуживают изучения и развития. В памяти знавших Наума Натановича людей он остался как яркий, энциклопедически образованный человек, готовьй прийти на помощь в трудную минуту и твердый в своих убеждениях.

Д. В. Аносов, В. Л. Гинзбург, А. Б. Жижченко, М. И. Монастырский, С.П. Новиков, Я.Г. Синай, М. А. Соловьев

\section{СПИСОК ТРУДОВ Н. Н. МЕЙМАНА}

[1] О корнях целых трансцендентных функций // Матем. сб. 1933. Т. 40. С. 521-528

[2] O $R$-продолжаемых полиномах // Труды 2-го Всесоюзного матем. съезда. 1934. Т. 2. С. 6-9 (совм. с Н.Г. Чеботаревым)

[3] Про полюси мероморфних функцій // Зап. Матем. об-ва (Харьков). 1937. Т. 4 (14). С. 97-104

[4] Sur les polinômes $R$-prolongeables // Матем. сб. 1938. Т. 3 (45). C. 591-650

[5] О продолжаемых полиномах, II. Об $R$-продолжаемых полиномах // Сб. памяти акад. Граве. 1940. C. $117-165$

[6] Об одной краевой задаче для полигармонических уравнений // Докл. АН СССР. 1941. T. 33. № 4. C. $275-278$

[7] К проблеме Эрмита-Гурвица для целых трансцендентных функций // Докл. АН СССР. 1943. T. 40. № 2. С. $55-58$

[8] K вопросу о распределении нулей целой функции // Докл. АН СССР. 1943. Т. 40. №5. C. $200-203$

[9] Оценка расстояния между соседними нулями для одного класса целых функций // Докл. AH CCCP. 1946. Т. 53. № 1. С. 11-14

[10] Об одном классе целых функций // Докл. АН СССР. 1948. Т. 62. № 3. С. 293-296

[11] О нулях линейных комбинаций одного класса целых функций // Докл. АН СССР. 1948. T. 62 . № 4. C. $453-456$

[12] Об одном классе целых функций // УМН. 1948. Т. 3. № 1 (23). С. 206-207

[13] Некоторые вопросы расположения нулей полиномов // УМН. 1949. Т. 4. № 6 (34). С. 154-188

[14] По поводу заметки Л. Б. Гейлера // УМН. 1949. Т. 4. № 6 (34). С. 194-195

[15] Проблема Рауса-Гурвица для полиномов и цельх функций // Труды Матем. ин-та АН CССР. 1949. Т. 26. С. 1-331 (совм. с Н. Г. Чеботаревым)

[16] Об оценках производных // УМН. 1950. Т. 5. № 2 (36). С. 158-159

[17] Об условиях, при которых производная мажоранты функции является мажорантой производной функции // Докл. АН СССР. 1950. Т. 71. № 4. С. 609-612

[18] О теореме единственности // Докл. АН СССР. 1951. Т. 81. № 5. С. $729-731$ (совм. с Б. М. Левитаном)

[19] Теоремы сравнения для аналитических функций // УМН. 1952. Т. 7. № 1 (47). С. 149-150

[20] Некоторые теоремы сравнения для аналитических функций // Докл. АН СССР. 1952. Т. 82. № 2. C. $185-188$

[21] Дифференциальные неравенства и некоторые вопросы распределения нулей целых и однозначных аналитических функций // УМН. 1952. Т. 7. № 3 (49). С. 3-62 ; Доп. и исправления: 1953. T. 8. №6 (58). C. $177-180$

[22] К теории уравнений в частных производных // Докл. АН СССР. 1954. Т. 97. № 4. С. 593-596

[23] Об уравнении теплопроводности // Докл. АН СССР. 1954. Т. 99. № 2. С. 209-212

[24] Некоторые теоремы аппроксимации, единственности и существования для уравнений в частных производных // УМН. 1955. Т. 10. № 1 (63). С. 207 
[25] О рекуррентных формулах для степенных сумм нулей бесселевых функций // Докл. АН CCCP. 1956. T. 108. № 2. C. 190-193

[26] Вывод пучка из ускорителя протонов с жесткой фокусировкой на энергию 7 Гэв // ПТЭ. 1956. Т. 3. С. 31-35 (совм. с В. В. Владимирским, Л. Л. Гольдиным и др.)

[27] Некоторые применения метода конечных разностей к дифференциальным уравнениям // Труды 3-го Всесоюзного матем. съезда (Москва, 1956 г.). Т. 1. М., 1956. С. 60

[28] Численные методы интегрирования уравнений в частных производных методом сеток // Труды 3-го Всесоюзного матем. съезда (Москва, 1956 г.). Т. 13. М., 1958. С. 92-100 (совм. с Л.Д. Ландау и И.М. Халатниковым)

[29] Принцип монотонности аргумента и дифференцирование неравенств // Докл. АН СССР. 1958. T. 120 . № 6. C. $1191-1193$

[30] О нулях одного класса неоднозначных функций // Докл. АН СССР. 1959. Т. 124. №6. C. $1211-1214$

[31] К теории функций классов $Н B$ и $B$ // Докл. АН СССР. 1959. Т. 125. № 5. С. 974-977

[32] К теории функций, наименее уклоняющихся от нуля в области // Докл. АН СССР. 1959. T. 126. № 2. C. $274-277$

[33] К теории полиномов, наименее уклоняющихся от нуля // Докл. АН СССР. 1960. Т. 130. № 2. C. $257-260$

[34] О наименее уклоняющихся от нуля полиномах с любым числом заданных коэффициентов // Докл. АН СССР. 1960. Т. 130. № 3. С. 503-506

[35] Решение основных задач теории полиномов и целых функций, наименее уклоняющихся от нуля // Труды ММО. 1960. Т. 9. С. 507-535

[36] Несколько теорем о нулях и экстремальных свойствах целых функций // Докл. АН СССР. 1961. T. 140. № 4. С. $755-758$

[37] О полноте нулей целых функций // Докл. АН СССР. 1961. Т. 141. № 4. С. 796-799

[38] К решению уравнений типа Чу-Мандельстама // ЖЭТФ. 1962. Т. 43. № 1. С. 181-184 (совм. с И. Гохфельд)

[39] Некоторые свойства аналитических функций // Вопросы физики элементарных частиц. Ереван, 1962. С. 223-232

[40] Об асимптотическом равенстве полных сечений частицы и античастицы // ЖЭТФ. 1962. T. 43. № 6. C. $2277-2280$

[41] Аналитические выражения для верхних границ констант связи в квантовой теории поля // ЖЭЭТ. 1963. Т. 44. № 4. С. 1228-1238

[42] Дисперсионные соотношения и общие свойства амплитуд рассеяния / / Вопросы физики элементарных частиц. Ереван, 1963. С. 121-130

[43] Функции ограниченного вида, классы $H_{\delta}$ и их приложения к дисперсионным соотношениям // УМH. 1963. T. 18. № 4. С. 208-210

[44] О дисперсионных соотношениях для показателей преломления и поглощения // ЖЭТФ. 1964. Т. 46. № 1. С. 240-242 (совм. с В. Л. Гинзбургом)

[45] Об асимптотическом равенстве дифференциальных сечений частиц и античастиц // ЖЭТФ. 1964. T. 46. № 3. C. 1039-1047

[46] Асимптотическая амплитуда рассеяния мезона на нуклоне // ЖЭТФ. 1964. Т. 46. № 4. C. $1502-1504$

[47] On the uper limit of the $\pi-N$ coupling constant // Phys. Lett. 1964. V. 10. № 1. P. 124-126 (with A. A. Slavnov)

[48] Принцип причинности и асимптотическое поведение амплитуды рассеяния // ЖЭТФ. 1964. T. 47. № 5. C. 1966-1983

[49] Принцип причинности и структура обобщенных функций, допустимых в физике // Тезисы научных сообщений Международного конгресса математиков, секция 12. М., 1966. С. 43

[50] $\mathrm{K}$ методу перевала // Вторая летняя школа по проблемам теории элементарных частиц. О тепя: Ин-т физики и астрономии Эст. ССР, 1967. С. 85-112 (совм. с В. А. Колкуновым и др.)

[51] Методы вычисления фазовых интегралов и распределений // ЯФ. 1969. Т. 9. № 3. С. 552-564 (совм. с В.А. Колкуновым и Е. С. Николаевским)

[52] Атлас распределений // Препринт. М.: ИТЭФ, 1967. С. 85-112 (совм. с О. Н. Балошиным, И. Н. Бородиной и др.) 
[53] Локальные теории поля и теорема "острие клина" // Тезисы докладов Всесоюзной конфб. по теории функций комплексного переменного. Харьков, 1971. С. 139 (совм. с М. И. Монастырским)

[54] Интеграл Пуассона-Стильтьеса для конечносвязной жордановой области // Докл. АН CCCP. 1971. T. 197. №6. C. 1272-1275

[55] Об оценке сверху потенциала плоского электростатического поля // Докл. АН СССР. 1972. T. 202. № 6. С. $1268-1270$

[56] К теории функций ограниченного вида // Докл. АН СССР. 1972. Т. 204. № 1. С. 34-37

[57] Перевальные контуры интегрального представления Зоммерфельда цилиндрических функций / / Препринт. М.: ИТЭФ, 1974 (совм. с И. М. Гохфельд и Е. С. Николаевским)

[58] Римановы поверхности, определяемые функциями Бесселя // Препринт. № 1. М.: ИТЭФ, 1975 (совм. с И. Н. Бородиной)

[59] Разложение по собственным функциям оператора Шредингера с комплексным потенциалом // Письма в ЖЭЭТФ. 1975. Т. 21. № 10. С. 621-624

[60] Functional integrals as integrals on locally noncompact groups with generalized measures // J. Math. Phys. 1984. V. 25. P. 1412-1433 ; Errata ibid. P. 3357

[61] Reminiscences of Landau // Frontiers of Physics. Oxford: Pergamon Press, 1989. P. 27-29

[62] What's what in path integration // Preprint IAS 906-94. Tel Aviv: The Mortimer and Raimond Sackler Institute of Advanced Studies, 1994 